\title{
Intellectual property and economic development in Germany: empirical evidence for 1999-2009
}

\author{
Andreas Bielig
}

Published online: 14 March 2012

(C) The Author(s) 2012. This article is published with open access at Springerlink.com

\begin{abstract}
The study analyses the relationship between the development of registered intellectual property and economic development in Germany. It shows a differing evidence for specific categories of intellectual property, indicating that not all intellectual property rights show a significant impact on the German Gross Domestic Product. Positive impacts have the stocks of patents, trademarks and designs. Applications for utility models surprisingly have a negative impact, what challenges developments of the economic theory. The empirical results delight also the specific structure of the technological and innovation system in the German economy, showing a national intellectual property profile with three key factors: product differentiation, complex technologies and design development.
\end{abstract}

Keywords Intellectual property · Growth · Patent · Trademark · Design · Utility model

JEL Classification $\mathrm{O} 11 \cdot \mathrm{O} 31 \cdot \mathrm{O} 34 \cdot \mathrm{O} 52$

\section{Introduction}

Intellectual property rights (IPR) and their role for economic growth stood early in the focus of economic analyses (Audretsch 1995). Major works concentrate on the role of patents (Mansfield 1986), some focus also on trademarks and designs (Goldstein and Strauss 2009). The results indicate varying evidence for the impact of intellectual property, depending on sector specific characteristics, enterprise structures or culture (Thurow 1997; Mansfield 1994). Nevertheless economic theory

\footnotetext{
A. Bielig $(\bowtie)$

Institute for World Economy Research and Polish German Academic Forum,

Warsaw School of Economics, ul. Rakowiecka 24, Office 16, 02-521 Warsaw, Poland

e-mail: post@andreasbielig.de
} 
suggests a positive influence of intellectual property on the generation of innovation and growth potentials and the practise in enterprises and markets supports this by intensive utilization processes. Especially the German economy showed in the past expansive IPR implementation efforts together with strict protection regimes, ensuring efficient monitoring and sanctioning of infringements of protected property. Therefore the question arises, if the IPR regime rewarded the German economy in the past with adequate chances of growth and prosperity for bearing the systemic costs of this strict IPR protection. The empirical study investigates the economic impact of registered intellectual property at the German Patent Office in Munich (DPMA) between 1999 and 2009 on the German economic development. It tries an answer to the question, what benefits or losses contributed registered patents, utility models, trademarks and designs in Germany to the economic performance in the last 10 years. From this perspective follows an attempt to derive implications about the German IPR profile, influencing the future economic development in Germany.

\section{The theory: intellectual property as a factor of economic development}

Intellectual property is regarded as an important instrument for innovation and technological progress, in some references beyond this even as a key factor (Albach and Rosenkranz 1995). Stronger IPR regimes and growing numbers of registered property rights for knowledge goods have catalytic functions by fostering creative and innovative activities of enterprises and individuals in the economy with economic incentives. Economic core of the concept is the reward of time-limited legal monopolies for the exploitation of the invention, what makes the creation or at least the investment in knowledge goods by economic subjects more attractive in comparison with a situation without protection (Machlup 1961).

According the theory, results of IPR protection are improved or new products and services on the market. Public awareness is also focussed on IPR-related problems: legal monopolies from IPR protection can lead to short term economic monopolies, thereby causing problems of market power and restricted competition (Bechtold 2007). To reduce the economic burden of monopolistic welfare losses two main parameters of IPR should be restricted for optimization of welfare (the scope and the duration of the protection), allowing spillovers of technological knowledge to imitators, potential competitors and the society over the time horizon (Kitch 1998; Towse and Holzhauer 2002). Economic subjects can utilize in this accumulation process a steadily growing stock of knowledge, leading to further economic development and prosperity of the society (Thumm 2000). The argument of technological diffusion, with its focus on dynamic efficiency aspects, represented since the advent of the first protection systems in Europe one of the main foundations of intellectual property protection (Kurz 2000). Only for trademark protection the exploitation by other economic subjects would lead to a dilution of the affected brand and destroy the necessary incentives for investments in the brand reputation, so the duration is unlimited. 
A complementary discussion in literature and practise draws also growing attention to negative aspects of excessive intellectual property protection and phenomena of abuse, resulting from the exclusion of potential users from exploitation of knowledge (Frietsch et al. 2010a and Beirat BMWT 2007). This debate targets on better balanced IPR regimes with improved participation of different stakeholder groups (for private use, research, education, public interests in general etc.), not questioning the relevance of intellectual property per se (Schmidtchen 2007).

\section{Theoretical model and empirical framework}

The multiple linear regression model on OLS basis estimates the economic impact of four main categories of intellectual property, asking for the significance of patents, utility models, trademarks and designs for economic growth, measured by the German GDP in actual prices in billion Euro. The main model is divided into estimations for stock and application data, registered at the national Patent Office DPMA (1999-2009), for differentiating the influences of stock and flow determinants on GDP.

Early studies showed for patents their significance on labour productivity and derived implication for innovation (Hoffmann 1965; Schmoch 1999). We assume the GDP to be a function Y of the accumulated intellectual property IPR in the economy, represented here by rights registered jointly at a discrete time $\mathrm{j}$ at the end of the year. Property rights belong to the accumulated stock $\mathrm{S}$ or are applications $\mathrm{A}$ for new protection rights.

$$
\mathrm{Y}_{\mathrm{n}, \mathrm{j}}=\mathrm{f}\left(\mathrm{IPR}_{\mathrm{j}}\right)=\mathrm{f}\left(\mathrm{IPR}_{\mathrm{S}, \mathrm{j}}, \operatorname{IPR}_{\mathrm{A}, \mathrm{j}}\right)
$$

Property rights IPR in the stock $S$ in $j$ contain accumulated stocks of patents $P$, utility models $\mathrm{U}$, trademarks $\mathrm{T}$ and designs $\mathrm{D}$.

$$
\mathrm{IPR}_{\mathrm{S}, \mathrm{j}}=\mathrm{P}_{\mathrm{S}, \mathrm{j}}+\mathrm{U}_{\mathrm{S}, \mathrm{j}}+\mathrm{T}_{\mathrm{S}, \mathrm{j}}+\mathrm{D}_{\mathrm{S}, \mathrm{j}}
$$

Applications A for intellectual property rights IPR in $\mathrm{j}$ contain applications for new rights to be registered for the future period during 1 year. They increase as flow variables the future stock $\mathrm{S}$ only if they meet the official requirements and no withdrawal during registration occurs. Therefore a separate examination is needed. Applications A for property rights IPR in $\mathrm{j}$ contain applications for patents $\mathrm{P}$, utility models $\mathrm{U}$, trademarks $\mathrm{T}$ and designs $\mathrm{D}$.

$$
\mathrm{IPR}_{\mathrm{A}, \mathrm{j}}=\mathrm{P}_{\mathrm{A}, \mathrm{j}}+\mathrm{U}_{\mathrm{A}, \mathrm{j}}+\mathrm{T}_{\mathrm{A}, \mathrm{j}}+\mathrm{D}_{\mathrm{A}, \mathrm{j}}
$$

We estimate the impact on GDP for both, stock (Eq. (3a)) and application variables (Eq. (3b)) with multiple OLS regression, assuming all IPR categories having significant impacts on GDP. The function for the GDP impact of intellectual property stocks $\hat{Y}_{n, S}$ estimates the joint impact of patent stocks $P_{S}$, utility models $U_{S}$, Trademarks $T_{S}$ and Designs $D_{S}$. The function for the GDP impact of intellectual property applications $\hat{\mathrm{Y}}_{\mathrm{n}, \mathrm{A}}$ estimates the joint impact of patent applications $\mathrm{P}_{\mathrm{A}}$, utility models $\mathrm{U}_{\mathrm{A}}$, Trademarks $\mathrm{T}_{\mathrm{A}}$ and Designs $\mathrm{D}_{\mathrm{A}}$. 


$$
\begin{gathered}
\hat{\mathrm{Y}}_{\mathrm{n}, \mathrm{S}}=\mathrm{b}_{0}+\mathrm{b}_{\mathrm{P}_{\mathrm{S}}} \mathrm{P}_{\mathrm{S}, \mathrm{j}}+\mathrm{b}_{\mathrm{U}_{\mathrm{S}}} \mathrm{U}_{\mathrm{S}, \mathrm{j}}+\mathrm{b}_{\mathrm{T}_{\mathrm{S}}} \mathrm{T}_{\mathrm{S}, \mathrm{j}}+\mathrm{b}_{\mathrm{D}_{\mathrm{S}}} \mathrm{D}_{\mathrm{S}, \mathrm{j}} \quad \text { with } \mathrm{j}=1,2, \ldots, 11 \\
\hat{\mathrm{Y}}_{\mathrm{n}, \mathrm{A}}=\mathrm{c}_{0}+\mathrm{c}_{\mathrm{P}_{\mathrm{A}}} \mathrm{P}_{\mathrm{A}, \mathrm{j}}+\mathrm{c}_{\mathrm{U}_{\mathrm{A}}} \mathrm{U}_{\mathrm{A}, \mathrm{j}}+\mathrm{c}_{\mathrm{T}_{\mathrm{A}}} \mathrm{T}_{\mathrm{A}, \mathrm{j}}+\mathrm{c}_{\mathrm{D}_{\mathrm{A}}} \mathrm{D}_{\mathrm{A}, \mathrm{j}} \quad \text { with } \mathrm{j}=1,2, \ldots, 11
\end{gathered}
$$

Data sources for all intellectual property categories are the Annual Reports of the German Patent Office in Munich from 2000 to 2010 (DPMA 2000-2010). Data for GDP developments are obtained from Statistical Yearbooks of the Federal Statistical Office in Wiesbaden (Destatis 2000-2010).

\section{Econometric analysis and results}

\subsection{GDP and intellectual property impact}

For examining the impact of stocks of patents, utility models, trademarks and designs on the German GDP according Eq. (3a) three regression functions are estimated. Table 1 presents the estimation results based on the approach and the data described above [regression functions results numbered (1), (2) and (3)]. The top panel shows the estimated standardized regression coefficients/beta-values (left column of each function) together with their marginal probabilities ( $p$ value) of rejecting the hypothesis that the coefficient is zero (right column in brackets). The asterisks $(*)$ indicate the level of statistical significance of the beta-value from $1 \%$ $(* * *)$ to below $10 \%$ (no indication). In the second lower panel criteria of the estimation quality of the function are presented. The number of observations is 11 for all estimations. $\mathrm{R}$ indicates the multiple correlations coefficient of the estimation, $\mathrm{R}^{2}$ shows the coefficient of determination, followed by the adjusted coefficient of determination (adjusted $\mathrm{R}^{2}$ ), s indicates the standard error of the residuals, $F$ shows the empirical $F$ value of the variance and finally shows the $p$ value of the $F$ test the significance level of rejecting the zero hypothesis for the estimation and indicates the quality of the estimation of the function. All estimations were also tested on heteroskedasticity, autocorrelation, multicollinearity and normal distribution to provide a high quality of the estimations.

The results of the first estimation model (1) for the GDP impact of the intellectual property stocks with patents $P_{S}$, utility models $U_{S}$, trademarks $T_{S}$ and designs $D_{S}$ as predictor variables (regressors) and the GDP as responding variable (regressand) show that designs and especially utility models are not at a significant level.

Therefore in the next regression model (2) the variable utility models is excluded as explaining variable leading to an estimation function with improved quality criteria of data fitting. Also $98.9 \%$ of the variance is explained by the estimation function, all predictors are significant at the $90 \%$-level, patents and trademarks also on the $99 \%$-level. The adjusted $\mathrm{R}^{2}$ value reaches its maximum for all estimations. Model (2) shows the best quality criteria of estimations for the IPR stocks. For control purposes a third regression function with two predictors (patents and trademarks), excluding the design stock as explaining variable is estimated in model (3). 
Table 1 Regression results intellectual property stocks and GDP in Germany 1999-2009

\begin{tabular}{llll}
\hline \multicolumn{4}{l}{ Dependent variable: GDP in billion Euro } \\
\cline { 2 - 4 } & $(1)$ & $(2)$ & $(3)$ \\
\hline Patents & $0.396(0.001)^{* * *}$ & $0.395(0.001)^{* * *}$ & $0.307(0.001)^{* * * *}$ \\
Utility models & $-1.22(0.563)$ & & \\
Trademarks & $0.866(0.000)^{* * *}$ & $0.909(0.000)^{* * * *}$ & $0.765(0.000)^{* * * *}$ \\
Designs & $0.310(0.121)$ & $0.229(0.062)^{*}$ & \\
Observations & 11 & 11 & 11 \\
$\mathrm{R}$ & 0.995 & 0.994 & 0.990 \\
$\mathrm{R}^{2}$ & 0.989 & 0.989 & 0.981 \\
Adjusted $\mathrm{R}^{2}$ & 0.982 & 0.984 & 0.976 \\
$\mathrm{~s}$ & 21.124 & 20.159 & 24.610 \\
$F$ & 139.422 & 203.978 & 203.647 \\
$F$ test $(p$ value $)$ & 0.000 & 0.000 & 0.000 \\
\hline
\end{tabular}

Source: own calculation on basis of DPMA (2000-2010) and Destatis (2000-2010)

Statistical significance: $* * * 1 \%$. ** $5 \%, * 10 \%$

With the independent variables patent and trademark stock the estimated function (3) shows, beside the constant component also changes in the lower coefficients for patent and trademark stocks and in the lower quality of the regression, indicated by a decreasing adjusted $\mathrm{R}^{2}$. The estimated control function (3) explains with $98.1 \%$ still a relatively big but slightly declining share of the variance. Also the standard error of the residuals $s$ of the estimation shows an increasing direction, what indicates growing inaccuracy in depicting the empirical basis. The $F$ test for the estimation remains also for the third model on a level of high significance, but for explaining the impact of IPR Stocks on the development of German GDP the estimated regression function (2) shows obviously a better adequacy with the data.

As a final result for the impact of IPR stocks on the GDP the model (2) indicates that three IPR stock categories were influencing the German GDP development positively from 1999 to 2009, patent stocks, trademark stocks and design stocks, what confirms the assumptions in the economic literature. It also shows, comparing the standardized coefficients beta, that trademark stocks influenced among all IPR categories the GDP with the strongest economic impact, leading by a wide margin. The relevance of trademark stocks for the German economic development is underlined by the highest significance level of the estimated predicting variables. In contrast to this, patents stocks as predictor show with a beta-value of 0.395 only a medium impact on the GDP development, but on a high significance level of the standardized coefficient. Design stocks contributed as explaining variable also to the German economic development, but from the relative perspective to a smaller degree than trademarks and patent stocks, combined with a lower significance only on the $90 \%$ level.

If the impact of applications of patents $\mathrm{P}_{\mathrm{A}}$, utility models $\mathrm{U}_{\mathrm{A}}$, trademarks $\mathrm{T}_{\mathrm{A}}$ and designs $\mathrm{D}_{\mathrm{A}}$ on the German GDP between 1999 and 2009 is estimated jointly 
according Eq. (3b), the first estimated model (1) shows regression function parameters in medium quality (see Table 2). Only utility model applications are significant on the $95 \%$ level, designs on $75 \%$. Both other IPR categories, patent and trademark applications show no significance for the GDP development in 1999-2009. If a causal correlation exists, as indicated by theoretical works, the data show here no evidence for this. The estimation explains $86.8 \%$ of the variance, the standard error of the residuals $\mathrm{s}$ is relatively low and the $F$ test shows a high significance of the first regression estimation (1). In contrast to theoretical considerations the coefficient and Beta-Value of the utility model applications show negative signs, what is confirmed also in control tests by the negative but narrow $95 \% \mathrm{CI}$ of the standardized regression coefficient, indicating a high quality of the Beta-Value.

In the second estimation model (2) utility models and designs are tested therefore on their potential for prediction of the GDP, rejecting patent and trademark applications as explanatory variables, with the result of a slightly improved estimation quality of function (2). The multiple correlation coefficient $\mathrm{R}$ declines on account of the predictor's reduction, also the explained share of the variance $\mathrm{R}^{2}$ with 86.0, but the improvement of the adjusted $\mathrm{R}^{2}$ and the standard error $\mathrm{s}$ of the estimation lead to an increased joint significance level of the estimation. Both independent variables utility model and design applications show an improved level of significance of the standardized coefficients, 95 and $90 \%$, remaining with the negative signs also indicated by the first function (1). The predictor reduction causes in the control test of the coefficients even a potentially quality improving narrowing of the $95 \% \mathrm{CI}$ of the Beta-Value for both coefficients, but for the variable design applications the alternating sign in the interval $-0,012 \leq \beta_{\mathrm{D}_{\mathrm{A}}} \leq 0,001$ suggests a rejection of designs in the next model (3).

Table 2 Regression results intellectual property applications and GDP in Germany 1999-2009

Dependent variable: GDP in billion Euro

(1)

$0.118(0.553)$

Patents

Utility models

Trademarks

Designs

Observations

$\mathrm{R}$

$\mathrm{R}^{2}$

Adjusted $\mathrm{R}^{2}$

$\mathrm{S}$

F

$F$ test ( $p$ value)

11

0.932

0.868

0.781

74.289

0.008
(2)

$-0.656(0.007)^{* * *}$

$-0.346(0.093)^{*}$

$-0.410(0.212)$

0.927

11

0.860

0.892

0.796

0.825

0.733

66.430

75.565

24.499

35.050

0.000

0.000

Statistical significance: *** $1 \%$. ** $5 \%, * 10 \%$ 
There the estimation shows slightly weakened quality parameters for the estimated function (3), with reductions in the explained variance of $79.6 \%$, adjusted $\mathrm{R}^{2}$ and an increased standard error $\mathrm{s}$ of the residuals, indicating that the model (2) has the best general data fitting quality, but lacks finally in the uncertainty of the regression coefficient of design applications. In model (3) the joint significance of the estimated function remains on a high level. The sign of the utility models coefficient remains negative, signalling a negative impact on GDP development, what is supported also in the control test by the $95 \% \mathrm{CI}$ of the Beta Value with $-0,080 \leq \beta_{\mathrm{U}_{\mathrm{A}}} \leq-0,036$. The significance of the standardized regression coefficient is improving in the last estimation function, indicating the relevance of the (negative) impact of utility model applications.

According these results, the analyses of the economic impacts of IPR applications show that, with the exception of utility models, no IPR application category indicates a significant impact on the German GDP from 1999 to 2009.

Surprising from the perspective of economic theory is the fact that utility model applications seem to have had a negative impact on the economic development, what is according to the Beta Value of serious relevance. The results show, that direct economic impacts of applications for patents, trademarks and (with respect to the mentioned $95 \%$ CI of the beta-value) also for designs on absolute German GDP developments were not significant in this period.

\subsection{Economic implications of the analysis}

The analysis indicates that in accordance with the theory the data show empirical strong evidence for the hypothesis, that intellectual property was having a significant impact on the economic development in Germany between 1999 and 2009. The result for the stock variables shows clear positive impacts with exception of the utility models category, where no sufficient significance level could be observed (Fig. 1).

In the analysis trademarks had the strongest impact with a Beta Value of 0.909, which seem to bear a considerable potential for fostering economic development. Trademarks are institutionalized working symbols for differentiation processes used by enterprises for technologies, products or services. They send signals to customers, indicating the origin of goods and transferring thereby information concerning quality, reputation, image or other relevant aspects for the demand side. Therefore they became in the past to a growing extent objects of huge managerial investment strategies for building up brand values in the long run (Shapiro 1983). Enterprises use trademarks as long term value creating instruments (Klein-Bölting and Maskus 2003). The building up process of reputation, mainly represented by the brand history, a unique and trustworthy brand image and a certain scope of visibility and reliability for consumers requires intensive investments in the form of sunk costs.

In contrast to this, the amortization is based on the accumulated brand capital. It allows evaluating the success of brand building by its enlargement of potentials for price margins, higher resistance against market shocks or potentials for leveraging 


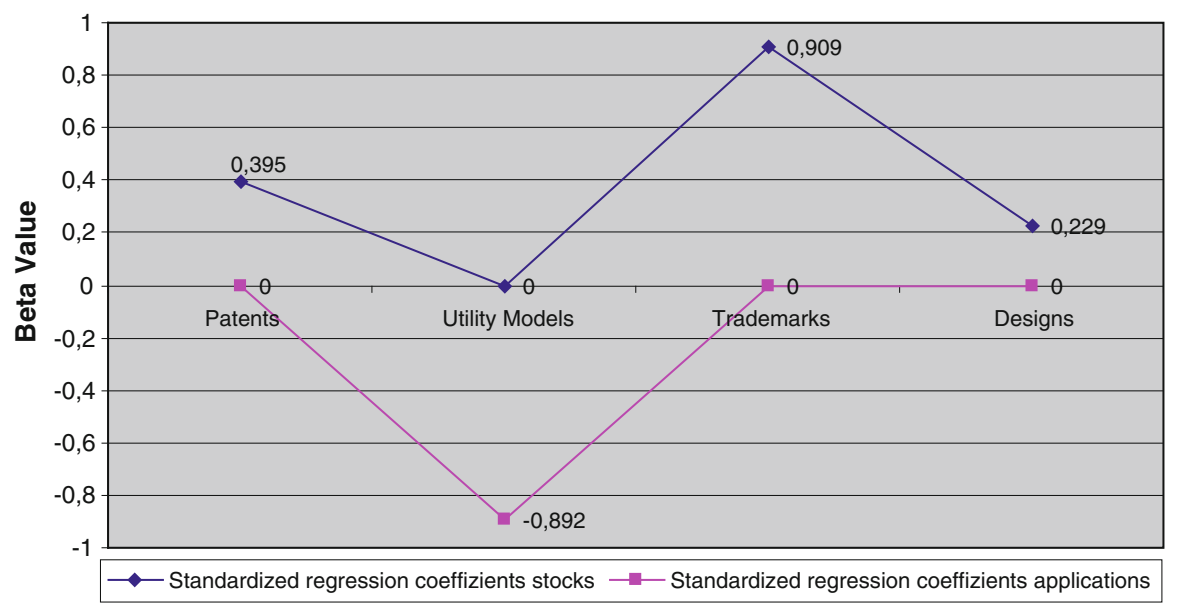

Fig. 1 Impact of intellectual property on German GDP 1999-2009. Source: own depiction

the brand to other products and markets by brand extension (Wessel 2004). This long term characteristic of trademarks is reflected by the unlimited duration, allowing periodically refinements, extensions or relaunches of brands for adjusting them to market changes. Trademarks are therefore a favoured instrument of intellectual property, used by enterprises for protection purposes in the longer run, especially if also flexibility concerning the specific protected object is required. In comparison with other optional, but time-limited IPR instruments, trademarks have the potential for protecting essential features or unique elements of products or services, also in other product categories, over their whole lifecycle. The data show an intensive use of trademarks by German and foreign enterprises with 778.000 registered rights hold on the German market in 2009. But there are also limiting conditions for economic trademark use, for instance aging processes of the brand image, high intensity of competition with other well-known brands in the market or the observable overextension of brands to other products, which show only a lower compatibility with the parent brand family and result therefore in brand dilution phenomena (Valtin 2005) (Fig. 2).

Patent stocks show in the analysis with a Beta Value of 0.395 the second strongest impact factor on the German GDP development. They are protecting technological inventions with a significant inventive step exceeding the existing state of technology in a specific field. Therefore economic incentives from patent protection are regarded as an important factor of technological progress and future economic development, what is confirmed by the results of the analysis. Surprisingly the present patent stock, with a high level of about 133.000 registered rights in 2009, shows only a medium impact on the German GDP at the aggregated level. It is comparable with the impacts of design stocks, standing in contrast to the outstanding public recognition of patents (Frietsch et al. 2010b) and the intensive patenting efforts of enterprises. 


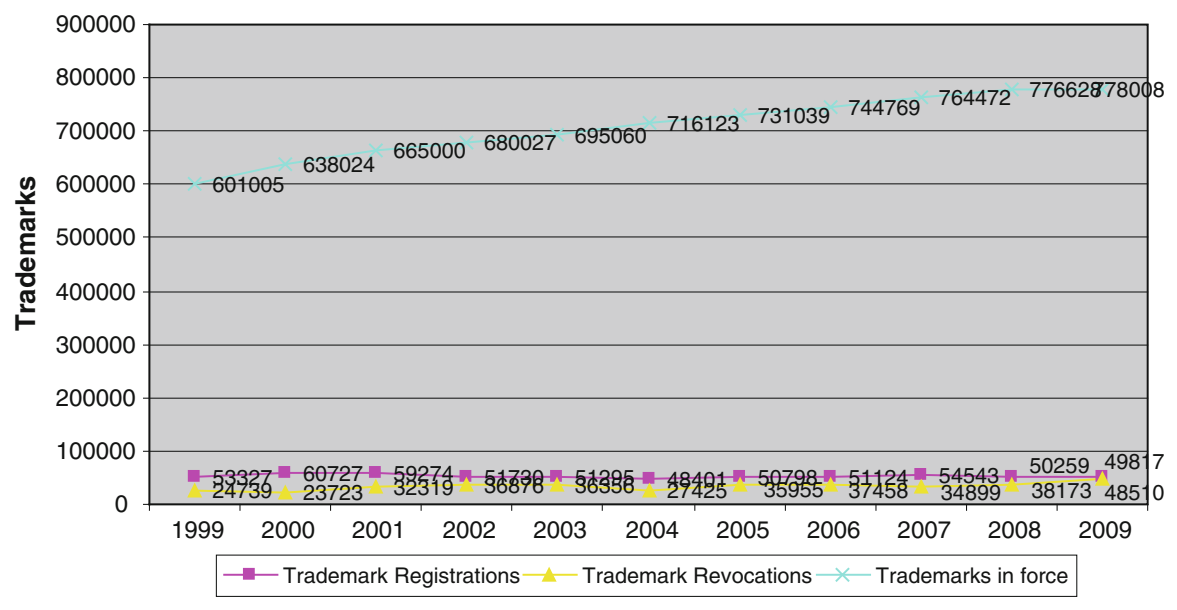

Fig. 2 Trademark stock at the DPMA 1999-2009. Source: own depiction

For explaining this fact, the facets of empirical reality and patent practise of businesses should be considered. Only a minority of high value patents is hold in force until the maximum duration of 20 years after several prolongations (Holzer 2004). Fast technology cycles, especially in ICT sectors, and changing market conditions with expanding competition pressure and developing consumer preferences devalue registered patent rights often very fast, so the contribution of many patents to GDP declines during time. Also the patent strategies, implemented in enterprises, shifted from the classical "pure" protection of inventions made by employees or research entities to a stronger consideration of strategic protection issues (Cohen et al. 2000). Patenting for the preservation of space for own technology developments, direct blocking of competitors, submarine strategies for bargaining purposes or pure patent trolling changed the patent policies of enterprises in the last years (Weber et al. 2007). The latter would mainly contribute only small to or, in the extreme cases, even harm GDP development, what leads to question for adequate institutional instruments for the prevention of welfare reducing potentials of patents (Shapiro 2002) (Fig. 3).

Design stocks are with 279.916 registered rights at the DPMA in 2009 the intellectual property category with the third strongest impact on the German GDP, what supports the literature hypothesis of their importance for prospering markets and economic development. The Beta value of 0.229 is in comparison with that of patent stocks smaller but shows nevertheless a considerable potential for addressing designs in the future more intensively for economic growth and as an important success factor of enterprises. The high significance level of $90 \%$ signalizes sufficient robustness of the results, so future efforts in theoretical and empirical economic research on economic effects of design protection would contribute substantially to a better and differentiated understanding of the intellectual property implications. This holds true especially for economic effects of interactions of available protection instruments for product and service markets. The use of 


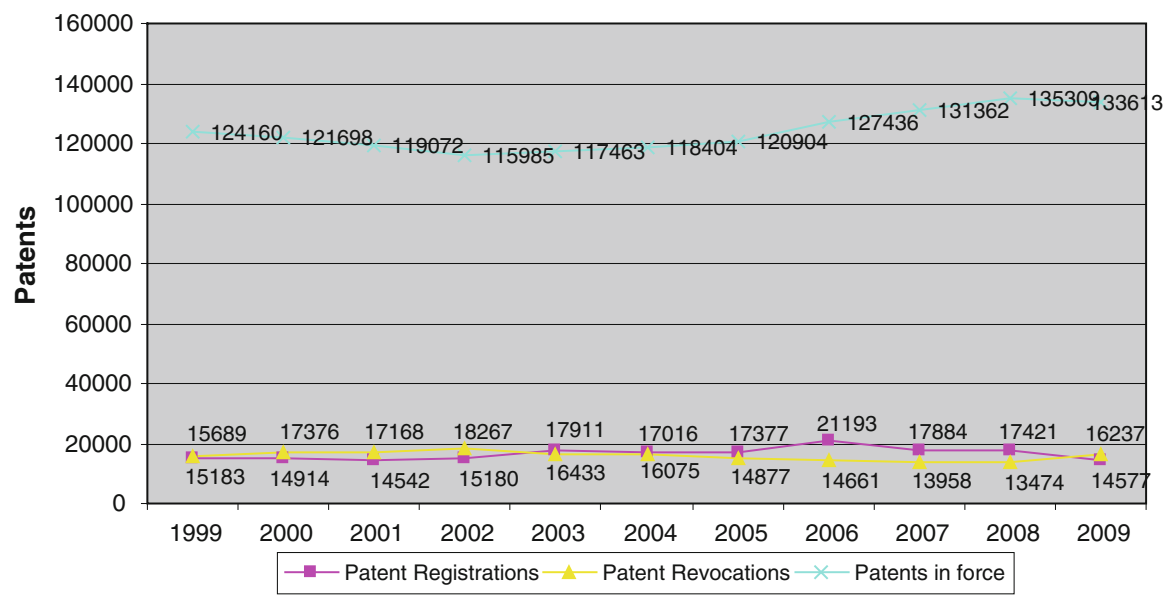

Fig. 3 Patent stock at the DPMA 1999-2009. Source: own depiction

complementary protection opportunities for extending the protection of specific good features, or of overlapping protection areas for improved and strengthened protection can lead for enterprises to a better individual economic performance. Design rights show here a considerable potential for the implementation of such a multi-categorial protection approach.

They protect specific characteristics of two- or three-dimensional patterns or models for a maximum duration of 25 years. Therefore they are the adequate long term protection instrument for outer shapes and appearances of products, if a specific degree of uniqueness is feasible (Mahr 2009). The long term character of designs serves in the business practice to a growing extent also for the marketing of enterprises, connecting the specific association of outer shapes and appearances of products by the customers with enterprise brands. Following this perspective, design is a valuable capital component of enterprises, serving as an object of strategic investment and exploitation processes. Hence it is an integrated part of the optimization approach of the organization and therefore essential for being protected by intellectual property rights under the constellation of steadily declining copy costs (Sokianos 2006). This holds true especially for enterprises and products with longer design histories, preserving specific outer characteristics carefully over decades, and it is less relevant for businesses with fast product life cycles, where the key factor in the market is the time-lead of pioneers (Fig. 4).

In contrast to the impacts of the stocks of trademarks, patents and designs no significant influence on the GDP development can be stated for utility model stocks, where in 2009 nearly 97.000 rights were registered at the DPMA. With these "small patents" applicants can protect new technical solutions, which contribute to the technological progress with smaller inventive steps than it is normally required for the reward of patents (Hoffmann 2008). The duration of the protection is with 10 years at the maximum shorter than for patents and also the registration process at the Patent Office differs, not containing any examinations for novelty, degree of 


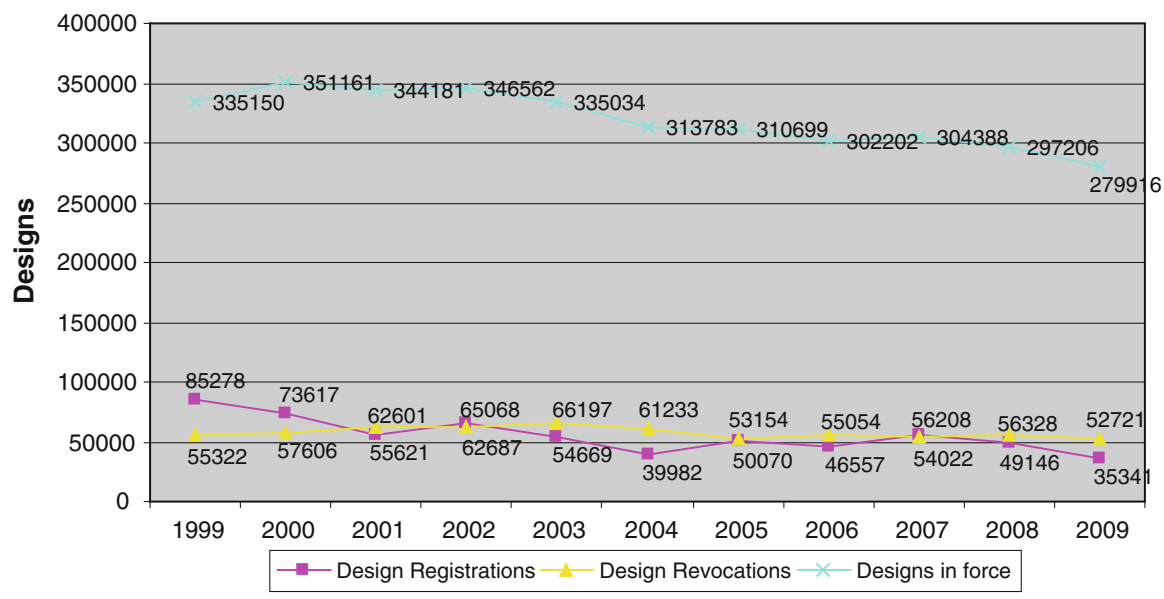

Fig. 4 Design stock at the DPMA 1999-2009. Source: own depiction

inventive step and commercial applicability, to enable more enterprises to obtain a fast and effective protection for their inventions. Designed for the short run, often used by enterprises only for the minimum duration of 3 years as a preliminary stage for a later obtained patent protection, the advantage points of utility models can be regarded also as systematic weaknesses. Relatively easy and fast to obtain without an intensive and careful examination procedure, sometimes the effective protection value of utility models is only possible to identify finally, if the registered (and not examined) right is contested by potential competitors before the court or infringed by imitators and copycats. This increases the incentive to apply rather for patents, if patent protection is also available, like for the most technologies of higher complexity (Königer 2009) (Fig. 5).

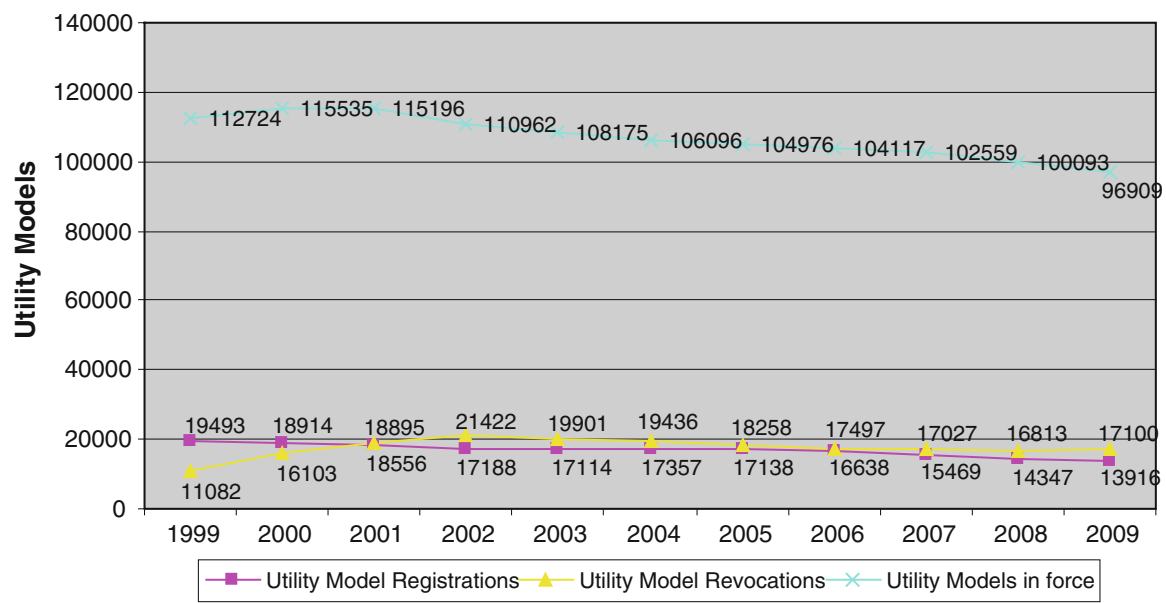

Fig. 5 Utility model stock at the DPMA 1999-2009. Source: own depiction 
The missing significance of the utility models stock for the German GDP development could be interpreted as a signal of small economic importance of the protected low-complex technologies for the economic development in Germany. Industry, research institutions and private inventors contribute according to this mainly with technology on higher standards and faster technological progress to GDP. Lower technology not only lacks on significant relevance at the present, but also steadily looses further shares for the future as indicated by the negative impact of applications for utility models on GDP. With a Beta Value of -0.892 the results of the analysis show a negative statistical correlation between the declining development of utility models applications and growing GDP. At the aggregated economy level decreasing numbers of applications with 17.376 applications in 2009 indicate shrinking medium term influences of utility models on GDP, if we consider them after the registration process also belonging to the property rights stock. The data from the period 1999-2009 actually don't show a significant negative impact of the utility models stock on GDP but in the case of a continued negative development of applications an increasing (negative) significance seems feasible for the stock variable in the future.

Utility models are especially important in industrial sectors with small, incremental product improvements, where mostly no huge R\&D investments require long term amortization strategies. For the German industry a declining demand for utility model protection and no (for the stock variable) or even a negative impact (for the applications variable) of this protection instrument can be observed. This empirical evidence is surprising, showing that intellectual property categories have not only varying impacts on the economic development, what questions the general assumption of welfare increasing effects of intellectual property, which has to be adjusted to a more differentiated perspective. The results also implicate (possible) negative influences of intellectual property, as indicated for utility model applications, depending on the industrial structures of the economy. Intellectual property therefore must be considered in a differentiated way, recognising first that not all what is possible to be protected is improving the economic performance and second we have to be aware of potentially negative impacts of intellectual property, what requires a careful consideration of influencing determinants of the economic outcomes (Fig. 6).

According to the results of the analysis only for utility models a (negative) significant impact on GDP can be derived from intellectual property application numbers. Patent, trademark and design rights applications have according my results no significant impact on the German GDP development, what challenges also the extensive research of the determinants of intellectual property applications.

\section{Conclusions}

As predicted by the theory, the analysis shows that intellectual property has an important impact on the economic development in Germany. But the dimensions differ among intellectual property categories and also among stock and application variables substantially. This empirical finding is supported also by the broad 


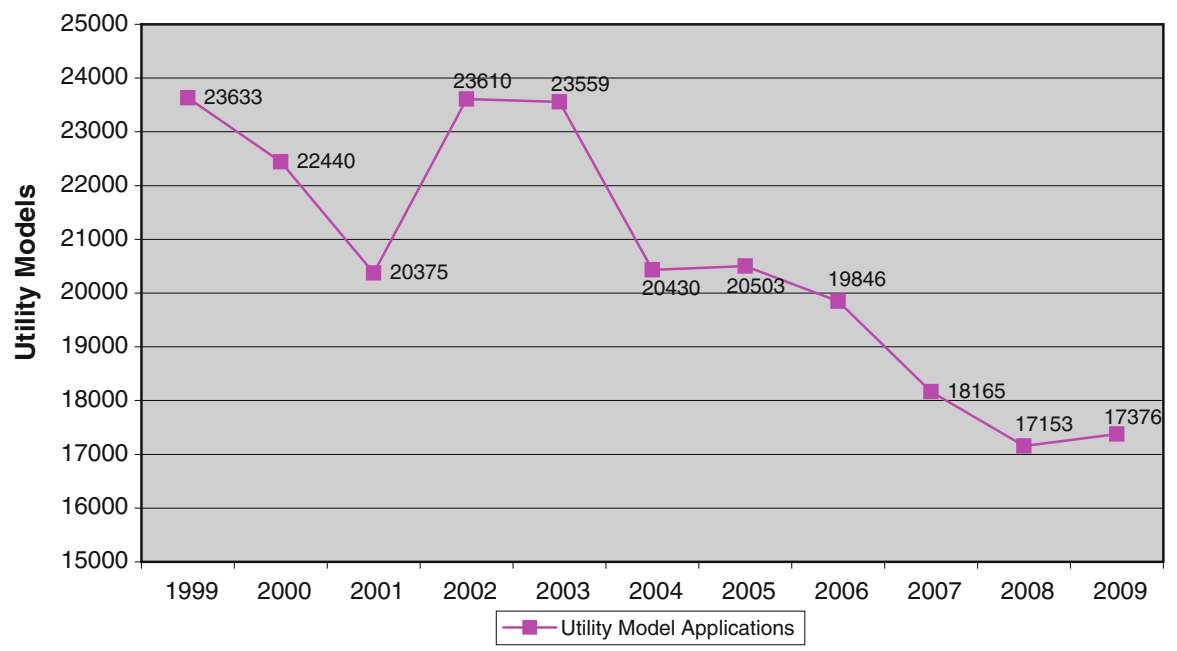

Fig. 6 Utility model applications at the DPMA 1999-2009. Source: own depiction

diversity of analysis approaches for the verification of the strongly differing economic effects of intellectual property on the microeconomic level, considering existing categorical differences in their legal design, in their business utilisation in practise by enterprises or concerning their specific market and innovation effects. The aim of this analysis is therefore a verification of the specific economic effects of intellectual property on the economic development on the macroeconomic level for the case of Germany. Measured by the German GDP between 1999 and 2009, the stocks of trademarks, patents and designs contribute positively to economic growth. Registered utility model rights didn't had a significant influence, what is surprising if the empirical evidence is considered, that applications for utility models show an impact on German GDP, but a negative one. Other IPR application categories have no significant impacts, what indicates that GDP development is mainly influenced and driven by existing stocks of intellectual property rights, with the exception of utility models. Here the trademark stocks have the strongest impact, then follow patent and design stocks, measured by the estimation coefficients. It is from the theoretical perspective not surprising, that trademarks correspond positively with the economic development. Remarkable is the result that their impact exceeds by far the importance of patents, which is only comparable with that of designs. Surprising is also the result, that applications for intellectual property rights have no impacts, with the exception of utility models, which show a negative influence.

The economic impact of IPR reflects also the structure of the German economy and its innovation system, examined from the empirical background of intellectual property utilisation. Key factors from the perspective of intellectual property protection are according the analysis results the protection of distinctive signs for enterprises, products and services with trademarks, what indicates the increasing importance of differentiation processes in the competition on the markets. Protection of technology and to a growing extent business processes with patents 
is the second important factor, mirroring the advanced standard of the technology and organizational position of the German economy in the global competition. In comparison with this positive contribution of intellectual property, for the protection of lower technology, as it is used mainly with utility models, no (for stocks) or even a negative (for applications) impact is visible. Economic development in Germany is from the intellectual property perspective mainly based on the development of higher R\&D intensive products and services, questioning the economic relevance of utility model protection, what is supported by the decreasing application numbers since 1999.

The third key factor of intellectual property for the German GDP development is according the analysis the protection of designs, what supports theoretical assumptions about positive economic contributions as well as entrepreneurial protection efforts in practise. Growing numbers of German enterprises recognise the economic importance of product design beside the "classical" functional characteristics of material, construction or technology. The development of matured product markets with close functional substitutes, showing only marginal differences in product characteristics, encourages enterprises to invest intensively in modern esthetical product solutions, targeting not only on customer preferences but also on product differentiation.

Although the results of the analysis outlined here examine in concreto the specific economic impacts of intellectual property on the German economic development, analogous general effects can be stated by other empirical investigations for the US economy and for Poland, as a new EU member state. The results allow deeper insights into their specific national industrial structures as well as into the intersectoral structural changes in these economies over the time.

Summarizing the results of the analysis, the German intellectual property profile is characterised by three main drivers with respect to future economic developments: (1) product differentiation with signalization of unique selling propositions protected via registered trademarks, (2) development of complex technologies and business processes protected via patents and (3) progressive design development protected via registered design rights. Considering the interdependences of these intellectual property categories and an adequate adaptation to market processes and institutional structures by enterprises as well as by political decision makers is decisive for the future economic success and development.

Open Access This article is distributed under the terms of the Creative Commons Attribution License which permits any use, distribution, and reproduction in any medium, provided the original author(s) and the source are credited.

\section{References}

Albach, H., \& Rosenkranz, S. (Eds.). (1995). Intellectual property rights and global competition. Towards a new synthesis. Berlin: Wissenschaftszentrum Berlin für Sozialforschung.

Audretsch, D. B. (1995). Intellectual property rights. New research directions. In H. Albach \& S. Rosenkranz (Eds.), Intellectual property rights and global competition. Towards a new synthesis (pp. 36-76). Berlin: WZB. 
Bechtold, S. (2007). Die Kontrolle von Sekundärmärkten. Eine juristische und ökonomische Untersuchung im Kartell- und Immaterialgüterrecht. Baden-Baden.

Beirat Bundesministerium für Wirtschaft und Technologie. (2007). Patentschutz und Innovation. Gutachten Nr. 1-07. Berlin.

Cohen, W. M., Nelson, R. R., \& Walsh, J. P. (2000). Protecting their intellectual assets. Appropriability conditions and why U.S. manufacturing firms patent (or not). National Bureau of Economic Research, Working Paper Series 7552.

Destatis. (2000-2010). Statistisches Jahrbuch für die Bundesrepublik Deutschland. Diverse years, Wiesbaden.

DPMA. (2000-2010). Jahresbericht. Diverse years, München.

Frietsch, R., et al. (2010a). The value and indicator function of patents, Studien zum deutschen Innovationssystem Nr. 15. Berlin: Fraunhofer Institute for Systems and Innovation Research and EFI.

Frietsch, R., et al. (2010b). Patent applications. Structures, trends and recent developments. Studien zum deutschen Innovationssystem Nr. 9. Berlin: Fraunhofer Institute for Systems and Innovation Research and EFI.

Goldstein, P, \& Strauss, J. (Eds.). (2009). Intellectual property in Asia. Law, economics, history and politics. Berlin, Heidelberg: Springer Verlag.

Hoffmann, W. (1965). Das Wachstum der deutschen Wirtschaft seit der Mitte des 19. Jahrhunderts. Enzyklopädie der Rechts- und Staatswissenschaft. Berlin, Heidelberg, New York.

Hoffmann, M. (2008). Mehrfachschutz geistigen Eigentums im deutschen Rechtssystem. München.

Holzer, W. (2004). Wie effizient ist der Patentschutz in der Praxis? In G. Kucsko (Ed.), Innovation und Rechtsschutz (pp. 41-49). Wien: MANZ'sche Wien.

Kitch, E. W. (1998). Patents. In P. Newman (Ed.), The new palgrave dictionary of economics and the law (pp. 13-17). London: Palgrave Macmillan.

Klein-Bölting, U., \& Maskus, M. (2003). Value brands. Markenwert als zentraler Treiber des Unternehmenswertes. Stuttgart.

Königer, K. (2009). Registration without examination. The utility model: A useful model? In W. Prinz zu Waldeck und Pyrmont, M. J. Adelman, R. Brauneis, J. Drexl, R. Nack (Eds.), Patents and technological progress in a globalized world. MPI Studies on intellectual property, competition and tax law (pp. 17-29). Berlin, Heidelberg: Springer Verlag.

Kurz, P. (2000). Weltgeschichte des Erfindungsschutzes. Erfinder und Patente im Spiegel der Zeiten. Köln, Berlin, Bonn.

Machlup, F. (1961). Die wirtschaftlichen Grundlagen des Patentrechts. Gewerblicher Rechtsschutz und Urheberrecht Int. part 1, 373-390; part 2, S. 473-482; part 3, 524-537.

Mahr, A. C. (2009). Designschutz. Der rechtliche Schutz der Produktgestaltung als Herausforderung an das System der Rechte des Geistigen Eigentums. Baden-Baden.

Mansfield, E. (1986). Patents and innovation. An empirical study. Management Science, 32(2), 173-181.

Mansfield, E. (1994). Intellectual property protection, foreign direct investment and technology transfer. Discussion Paper 19. World Bank, Washington, DC.

Schmidtchen, D. (2007). Die Beziehung zwischen dem Wettbewerbsrecht und dem Recht geistigen Eigentums-Konflikt, Harmonie oder Arbeitsteilung? In S. Bechtold, A. Ohly, J. Schade, D. Schmidtchen, P. Oberender (Eds.), Wettbewerb und geistiges Eigentum. Schriften des Vereins für Socialpolitik (pp. 9-46). Bd. 316, Berlin: Duncker \& Humblot.

Schmoch, U. (1999). Eignen sich Patente als Innovationsindikatoren? In R. Boch (Hrsg.), Patentschutz und Innovation in Geschichte und Gegenwart. Studien zur Technik-, Wirtschafts- und Sozialgeschichte (pp. 113-123). Frankfurt/Main, Berlin, Bern, New York, Paris, Wien: Peter Lang Verlag.

Shapiro, C. (1983). Premiums for high quality products as returns to reputations. Quarterly Journal of Economics, 98, 659-679.

Shapiro, C. (2002). Navigating the patent thicket. Cross licences, patent tools and standard setting. In A. B. Jaffe, J. Lerner, \& S. Stern (Eds.), Innovation policy and the economy (pp. 118-150). London: Cambridge/Mass.

Sokianos, N. P. (2006). Produkt- und Konzeptpiraterie. Herausforderungen im erweiterten Unternehmensnetzwerk. In N. P. Sokianos (Ed.), Produkt- und Konzeptpiraterie. Erkennen, vorbeugen, abwehren, nutzen, dulden (pp. 15-54). Wiesbaden: Gabler Verlag.

Thumm, N. (2000). Intellectual property rights. National systems and harmonisation in Europe. Contribution to economics. Heidelberg, New York: Physica Verlag. 
Thurow, L. C. (1997). Needed: A new system of intellectual property rights. Havard Business Review, September/October, 75, 95-103.

Towse, R., \& Holzhauer, R. (2002). Introduction. In R. Towse \& R. Holzhauer (Eds.), The economics of intellectual property (Vol. I, pp. xi-xxxii). Cheltenham, Northampton: Edward Elgar Publishing.

Valtin, A. (2005). Der Wert von Luxusmarken. Determinanten des konsumentenorientierten Markenwerts und Implikationen für das Luxusmarkenmanagement, Wiesbaden.

Weber, G., Hedemann, G. A., \& Cohausz, H. B. (2007). Patentstrategien. Köln, Berlin, München.

Wessel, I. (2004). Beurteilung von Markenstrategien im Outfitbereich. Eine empirische Analyse auf Basis von Erfolgsfaktoren. Wiesbaden. 